\title{
Experimental Research on Reflection-based Deep Learning
}

\author{
Hao Zhang \\ College of Journalism and Communication \\ Yangzhou University \\ Yangzhou, Jiangsu
}

\begin{abstract}
Reflection-based deep learning, essentially a type of deep learning, aims to promote deep learning by developing reflective learning ability. In order to test "the promoting effects of reflection on deep learning", according to the process model of reflection-based deep learning, we designed the experimental scheme. Firstly, through the pretest questionnaire, we determined the experimental subjects according to their learning capacity level; then through the specific teaching interventions, we guided the experimental class to carry out their reflective learning activities throughout the whole class; finally through variance analysis of the written test and the work creation, we confirmed that the model of reflection-based deep learning had certain feasibility, furthermore the reflection activities really can effectively promote students' deep learning.
\end{abstract}

Keywords-reflection; reflective learning; deep learning; reflection-based deep learning

\section{BACKGROUND OF EXPERIMENTAL RESEARCH}

As early as the mid of 1950s, Marton and Säljö were the first to start the experimental study of deep learning [1]. Around the same period, many other researchers developed the research on deep learning from different perspectives. Through the analysis of deep learning scales developed by Biggs, Entwistle and Ramsden, Nelson Laird and his colleagues found that deep learning can be deconstructed into three component parts: high-order learning, integrative learning, or reflective learning [2]. In other words, all of them are the concrete forms of deep learning. Reflection-based deep learning is mainly about "how to promote deep learning by reflection".

Based on lots of literature analysis, we had demonstrated the mutual promotion between deep learning and reflective learning from the theoretical level, and through incorporating the ideas about reflection into the general process of deep learning, constructed the process model of reflection-based deep learning as shown in Figure 1[3]. Now we will put these theories into practice, which is to combine with the relevant courses, design the experimental scheme and develop the teaching activities.

\author{
Xiujuan $\mathrm{Wu}$ \\ Zhejiang Yuexiu University of Foreign Languages \\ Shaoxing, Zhejiang \\ Yuzhu_2109@126.com
}

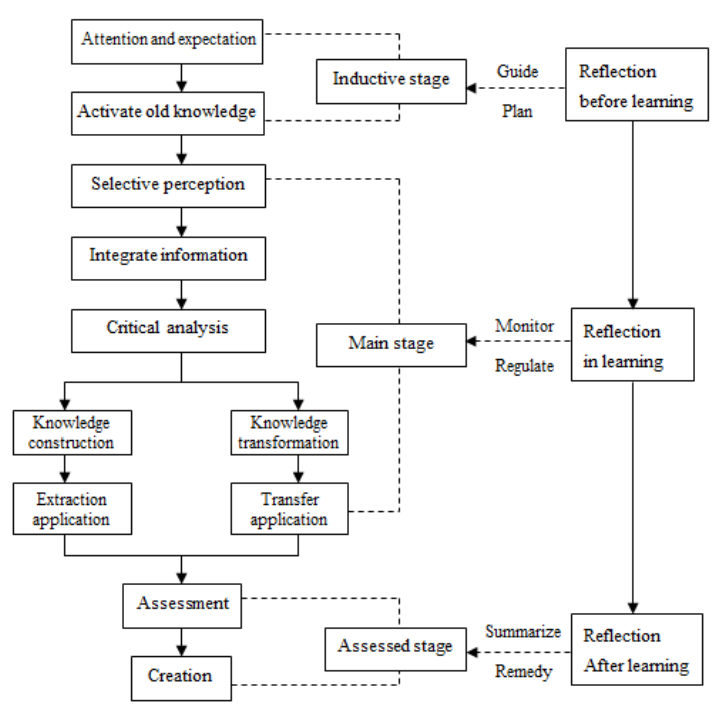

Fig. 1. The process model of reflection-based deep learning

\section{EXPERIMENTAL DESIGN AND IMPLEMENTATION}

\section{A. Experimental design}

Deep learning aims to achieve overall learning objectives and develop high-order thinking ability [4]. So is reflectionbased deep learning, which is a special kind of deep learning. As promoting learning is the common character of deep learning and general learning, we can assess deep learning from the traditional point of cognition, motor skills and emotion. Moreover, to develop high-order thinking ability is its particularity, so we also need to measure learnings' thinking structure level and identify their cognitive development level according to Biggs' SOLO(Structure of the Observed Learning Outcome) taxonomy.

In order to examine the promoting effects of reflection on deep learning, a quasi-experimental study is designed, which has both the experimental group and the compared group at the pre-test and the post-test. And put forward the following three hypotheses: firstly, reflection can help attain the intellectual target of deep learning, especially the high-level cognition of deep knowledge and complex concept; secondly, reflection can promote learnings' understanding of the problem, and then 
help them get complex learning outcomes and high-level thinking ability; thirdly, reflection can effectively facilitate the learners' grasp of information technology skills and improve their problem-solving ability and practical-creating ability.

\section{B. Experimental implementation}

In the preparation stage, through the discussion with cooperative teacher, we determine the teaching contents and adjust the teaching plan accordingly. Then in the implementation phase, we observe the two groups' teaching for eight weeks and properly modify the experimental material. It is composed by pre-test phase, treatment phase, and post-test phase.

\section{1) Pre-test phase}

In order to ensure the experimental effect, we should choose two classes as similar as possible. According to the outcomes of questionnaire survey and variance analysis, we determine to take class 4 and class 5 as the experimental subjects. And randomly class 4 is selected as experimental class to adopt the model of deep learning with reflection, while class 5 is selected as compared class to adopt the model of deep learning without reflection.

\section{2) Treatment phase}

Knowledge content is the object for learners to recognize and practice [5]. Spiro considers that knowledge can be divided into well-structured knowledge and ill-structured knowledge, accordingly learning can be called primary learning and advanced leaning. Deep learning aims to solve the ill-structured problem of the real social situation and complex technology environment through the integration of multi-dimensional knowledge and the construction of new knowledge and meaning [6]. So the involved knowledge should be complex, open and ill-structured, and also easy to integrate, construct and contextualize. Reflection-based deep learning intents to discover, inquire and solve problem by the reflection and regulation of learning process and outcome, and then promote the development of high-level thinking and the realization of deep leaning. So we can say that the two key points of reflection-based deep learning are reflection and problemsolving. Hence we choose the chapter "the acquisition and processing of image" from information technology course in senior middle as the teaching content of our experiment. And based on the process model of reflection-based deep learning and the teaching objectives of the experimental section, we design the experimental program and put it into practice [7]. The concrete process of reflection is as following:

\section{a) Reflection in the inductive stage}

Before the new class, we will guide learners to review the old knowledge by creating the problem situation- how to make a poster with texts and pictures. And then elicit the new teaching content by asking the question-how to deal with the pictures. Meanwhile, require learners to fill in "the pre-course self-test form".

\section{b) Reflection in the main stage}

The reflection in class mainly follows the "ConflictReflection-Generation" mode, as shown in Figure 2 when lecturing on "the classification and comparison of graphs and pictures", that is, to create the cognitive conflicts by showing two different kinds of images, and then require learners to generate solution to eliminate them through reflecting old knowledge. Besides, this reflection can also follows the "Variant-Reflection-Migration" mode, as shown in Figure 3, to regulate the process of variant practice through reflection and promote the exploration and solving of new problems, for example when asking learners to design and create their own work by Photoshop. Meanwhile, require them to fill in the record form about work designing and creating, which aims to guide learners to reflect, extract the relevant knowledge and skills, and regulate their work creation.

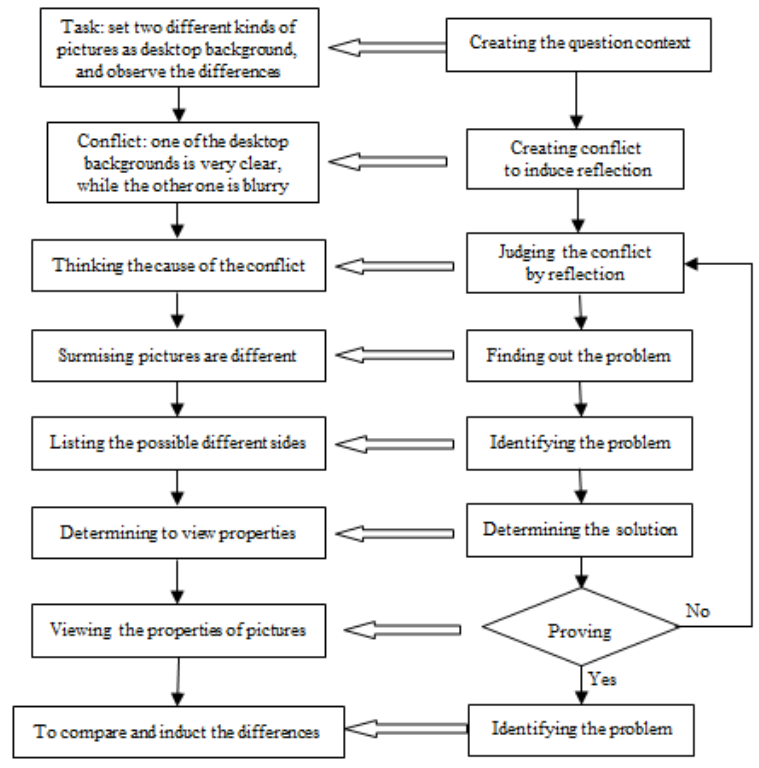

Fig. 2. The Reflection following "Conflict-Reflection-Generation" mode

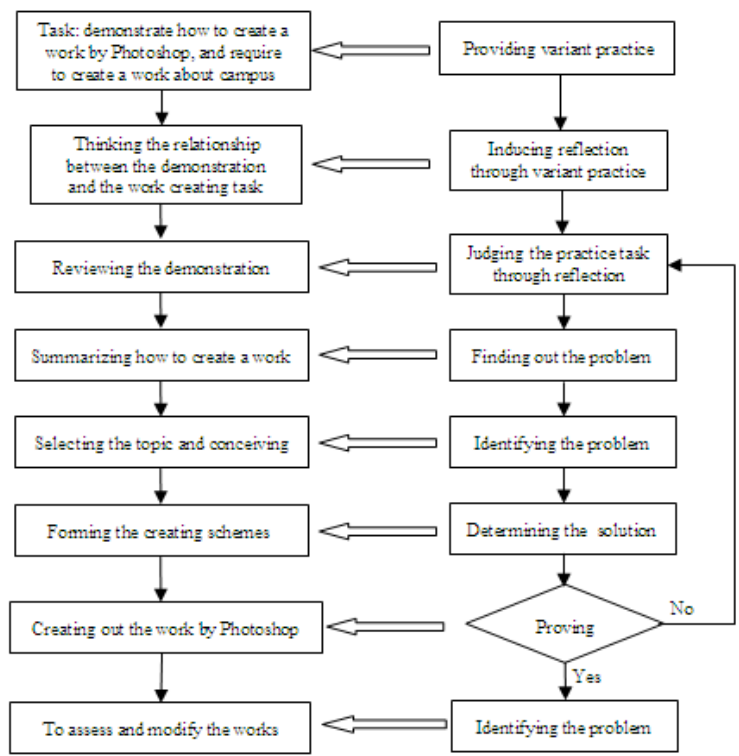

Fig. 3. The Reflection following "Variant-Reflection-Migration" mode

c) Reflection in the evaluated stage

After every class, learners are required to reflect on their classroom learning process and result by fill in a record form, 
so that the deficiencies of the learning may be discovered and solved timely, and the new knowledge may be created and applied to address complex new issues. At the end of the whole chapter, learners are required to reflect by fill in a selfevaluation form.

\section{3) Post-test phase}

In the post-test, both classes are required to submit their works and have a written test. Then according to the experimental hypotheses, their works and papers are scored from these three aspects. Through the statistical analysis of these scores, we can find whether there is a significant difference between the experimental class and compared class. So we can know whether reflection can promote deep learning or not.

\section{EXPERIMENTAL RESULT AND ANALYSIS}

\section{A. Statistic analysis of test score}

1) Variance analysis of test score

Through the independent sample t-test of the test scores and the score of surface learning, deep learning and thinking structure, all the scores of experimental class exceed the compared class. As shown in table 1, there is significant difference between them.in other words, after the teaching intervention, the learning effect of experimental class is much better than the compared class. It seems that the model of deep learning with reflection can contribute to promote both deep learning and surface learning.

TABLE I. THE INDEPENDENT SAMPLE T-TEST RESULTS OF TEST SCORE BETWEEN THE EXPERIMENTAL CLASS AND COMPARED CLASS

\begin{tabular}{|c|c|c|c|c|c|c|}
\hline Compared Items & Classes & Number & Average score & T value & P value & Degree of the Differences \\
\hline \multirow{2}{*}{ the total score of the test } & experimental & 52 & 50.56 & \multirow{2}{*}{4.915} & \multirow{2}{*}{$0.000<0.01$} & \multirow{2}{*}{ very significant } \\
\hline & compared & 53 & 43.83 & & & \\
\hline \multirow{2}{*}{ the score of surface learning } & experimental & 52 & 25.12 & \multirow[b]{2}{*}{2.430} & \multirow{2}{*}{$0.017<0.05$} & \multirow{2}{*}{ significant } \\
\hline & compared & 53 & 23.24 & & & \\
\hline \multirow{2}{*}{ the score of deep learning } & experimental & 52 & 18.42 & \multirow{2}{*}{5.551} & \multirow{2}{*}{$0.000<0.01$} & \multirow{2}{*}{ very significant } \\
\hline & compared & 53 & 15.00 & & & \\
\hline \multirow{2}{*}{ the score of thinking structure } & experimental & 52 & 7.02 & \multirow{2}{*}{3.240} & \multirow{2}{*}{$0.002<0.01$} & \multirow{2}{*}{ very significant } \\
\hline & compared & 53 & 5.58 & & & \\
\hline
\end{tabular}

2) Variance analysis of SOLO level

According to the score of thinking structure, we know that experimental class is better at the response to subjective problem. However, the difference of the score hasn't shown the complexity of their thinking structure and SOLO level. So we need to do a content analysis on their responses. That is to classify every response into the matching SOLO level, and have a chi-square test on their quantity. From table 2, we know that on first compared item, there is significant difference, and most of experimental class are in the level of multi-structure and relational structure, that is to say that their thinking structure is more complex; on second compared item, there is no significant difference, both classes are in the level of multi-structure; on third compared item, there is very significant difference, and much more students of experimental class are in the level of relational structure, although most students of both classes are in the level of multi-structure and relational structure.

TABLE II. THE QUANTITY DIFFERENCE ON THE SOLO LEVELS BETWEEN THE EXPERIMENTAL CLASS AND COMPARED CLASS

\begin{tabular}{|c|c|c|c|c|c|c|c|}
\hline \multirow{2}{*}{ Compared Items } & \multirow{2}{*}{ Classes } & \multicolumn{4}{|c|}{ SOLO Levels } & \multirow{2}{*}{$\chi 2$ value } & \multirow{2}{*}{$P$ value } \\
\hline & & Pre-structure & Uni-structure & Multi-structure & Relational structure & & \\
\hline \multirow{2}{*}{$\begin{array}{l}\text { choosing reason of } \\
\text { the e-greeting-card }\end{array}$} & experimental & 6 & 7 & 20 & 19 & \multirow{2}{*}{9.909} & \multirow{2}{*}{0.019} \\
\hline & compared & 13 & 13 & 20 & 7 & & \\
\hline \multirow{2}{*}{$\begin{array}{l}\text { modifying advise of } \\
\text { the e-greeting-card }\end{array}$} & experimental & 2 & 15 & 33 & 2 & \multirow{2}{*}{0.797} & \multirow{2}{*}{0.850} \\
\hline & compared & 1 & 17 & 34 & 1 & & \\
\hline \multirow{2}{*}{$\begin{array}{c}\text { the solution of the } \\
\text { hard-sending problem }\end{array}$} & experimental & 1 & 21 & 30 & 0 & \multirow{2}{*}{16.992} & \multirow{2}{*}{0.000} \\
\hline & compared & 1 & 42 & 10 & 0 & & \\
\hline
\end{tabular}

\section{B. Statistic analysis of work creation}

The skills of information technology can be better grasped, improved and assessed only in practice. Therefore, combining with students' life situation, we require them to create "Campus life posters" by Photoshop. On the one hand, their creating process can promote their understanding, transferring and application of relevant skills; on the other hand, their final work can show us their mastery degree of relevant skills and their creative ability.

\section{1) Frequency analysis of work score}

According to the work evaluation scale, we score every work, and perform statistic analysis and frequency analysis of the scores. As shown in table 3, much more students of experimental class get high score, while the same number of both class get the medium score. On the whole, the work level of experimental class exceeds compared class.

TABLE III. THE GROUP DISTRIBUTION OF THE WORK SCORE IN EACH CLASS

\begin{tabular}{|c|c|c|c|c|}
\hline items & \multicolumn{2}{|c|}{ experimental class } & \multicolumn{2}{c|}{ compared class } \\
\cline { 2 - 5 } groups & number & percent & number & percent \\
\hline Above 23points & 22 & $41.5 \%$ & 11 & $21.2 \%$ \\
\hline $19 \sim 22$ points & 25 & $47.2 \%$ & 25 & $48.1 \%$ \\
\hline 16 19points & 6 & $11.3 \%$ & 1 & $17.3 \%$ \\
\hline Below 16points & 0 & 0 & 7 & $13.4 \%$ \\
\hline
\end{tabular}




\section{2) Variance analysis of work score}

In order to prove the promotion of reflection on the application of information technology skills and more clearly show the difference of the work creation between experimental class and compared class, we compare their total score of work creation and the scores of eight concrete dimensions (including format specification, brush using, text material, picture material, self-selection content, color matching, theme expression and overall effect) by using independent sample t-test. As shown in table 4, the whole effect of the works from experimental class is much better than compared class.

TABLE IV. THE INDEPENDENT SAMPLE T-TEST RESULTS OF WORK SCORE BETWEEN THE EXPERIMENTAL CLASS AND COMPARED CLASS

\begin{tabular}{|c|c|c|c|c|c|c|}
\hline Compared Items & Classes & Number & Average score & T value & P value & Degree of the Differences \\
\hline \multirow{2}{*}{ total score } & experimental & 53 & 21.25 & \multirow{2}{*}{3.781} & \multirow{2}{*}{0.000} & \multirow{2}{*}{ very significant } \\
\hline & compared & 52 & 19.52 & & & \\
\hline \multirow{2}{*}{ format specification } & experimental & 53 & 1.98 & \multirow{2}{*}{0.861} & \multirow{2}{*}{0.391} & \multirow{2}{*}{ not significant } \\
\hline & compared & 52 & 1.95 & & & \\
\hline \multirow{2}{*}{ brush using } & experimental & 53 & 3.74 & \multirow{2}{*}{1.762} & \multirow{2}{*}{0.081} & \multirow{2}{*}{ not significant } \\
\hline & compared & 52 & 3.46 & & & \\
\hline \multirow{2}{*}{ text material } & experimental & 53 & 2.92 & \multirow{2}{*}{0.415} & \multirow{2}{*}{0.679} & \multirow{2}{*}{ not significant } \\
\hline & compared & 52 & 2.90 & & & \\
\hline \multirow{2}{*}{ picture material } & experimental & 53 & 3.75 & \multirow{2}{*}{2.997} & \multirow{2}{*}{0.004} & \multirow{2}{*}{ very significant } \\
\hline & compared & 52 & 3.41 & & & \\
\hline \multirow{2}{*}{ self-selection content } & experimental & 53 & 2.08 & \multirow{2}{*}{3.352} & \multirow{2}{*}{0.001} & \multirow{2}{*}{ very significant } \\
\hline & compared & 52 & 1.56 & & & \\
\hline \multirow{2}{*}{ color matching } & experimental & 53 & 1.87 & \multirow{2}{*}{0.983} & \multirow{2}{*}{0.328} & \multirow{2}{*}{ not significant } \\
\hline & compared & 52 & 1.81 & & & \\
\hline \multirow{2}{*}{ theme expression } & experimental & 53 & 1.72 & \multirow{2}{*}{1.663} & \multirow{2}{*}{0.099} & \multirow{2}{*}{ not significant } \\
\hline & compared & 52 & 1.60 & & & \\
\hline \multirow{2}{*}{ overall effect } & experimental & 53 & 3.19 & \multirow{2}{*}{2.098} & \multirow{2}{*}{0.039} & \multirow{2}{*}{ significant } \\
\hline & compared & 52 & 2.83 & & & \\
\hline
\end{tabular}

Concretely speaking, the differences exist in these dimensions which are picture material, self-selection and overall effect. But there is no significant difference in other dimensions. It may be contributed by their design and planning before work creation and their reflection and assessment in the process of work creation. Because the experimental class is required to reflect frequently by writing the record form of work creation, while the compared class has no any other requirement.

\section{EXPERIMENTAL CONCLUSION AND RETHINKING}

\section{A. Experimental conclusion}

Through the experiment, we confirm that the model of reflection-based deep learning has certain feasibility in the course teaching of information technology. The reflection activities run throughout all the class .Before a new class, students of experimental class review the old knowledge, preview the new knowledge and build up their relationship; in the class, they are guided to reflect in cognitive conflict and variant practice; after the class, they strengthen their learning through self-assessment. All these reflection strategies are useful for deep leaning. In addition, we find that reflection really can effectively promote deep learning. No matter in the written test or in the work creation, experimental class who participates in many reflection activities, performs much better than compared learning. This is basically identical with the original hypothesis of our experiment.

\section{B. Experimental rethinking}

Although this experiment has made certain achievements, due to the limitation of research time and personal ability, there are still some problems and the insufficiencies, which need to be further studied and solved. For instance, based on the relevant learning theories and the feature of the experimental course, we have designed some assessment measures including written test, performance task and the work evaluation scale, but their effect on assess deep leaning need to be testified, after all, there is no unified criterion on the evaluation of deep learning. Moreover, it still needs to look for ways to promote high-level cognition, since the cognitive response level of deep learning corresponds to the extent structure level and the relational structure level according to Biggs' SOLO taxonomy, while in our experiment, the number of students in these two levels is not ideal. Besides, reflection-based deep learning is a gradual process, so it is necessary for us to deepen the practical research by expanding the research object and combining with other course.

\section{REFERENCES}

[1] Marton F,Saljo R. On Qualitative Differences in Learning: I-Outcome and Process[J]. British Journal of Educational Psychology, 1976,(46): 4-11.

[2] Nelson Laird,T.F., Shoup,R.,Kuh,G.D. Measuring Deep Approaches to Learning Using the National Survey of Student Engagement[C]. The Annual Forum of the Association for Institutional Research, 2006:1-21.

[3][7] Wu Xiujuan,Zhang Hao,Ni Changqing. Research on the Connotation and Process of Reflection-based Deep Learning[J]. e-Education Research.2014,(12):23-28

[4] Zhang Hao,Wu Xiujuan,Wang Jing. Study on the Evaluation Theoretica Structure Building of Deep Learning [J]. China Educational Technology,2014,(7):51-55.

[5] Zhang Jing, Chen Youqing. Transformation of IT-based Instruction Method towards Deep Learning $[\mathrm{J}]$. China Educational Technology,.2013,4:20-24.

[6] Hao Zhang, Xiujuan Wu. The Study on the Connotation and Cognitive Theory Foundation of Deep Learning $[\mathrm{J}]$. China Educational Technology,2012,(10):7-11 